\title{
Innovative Art Therapy Activities Used by Undergraduate Student Nurses with Mental Health Patients
}

\author{
Robyn Rice, Joyce Hunter, Ann Raithel, Robin Kirschner \\ Chamberlain College of Nursing, Downers Grove, Illinois, United States \\ Email address: \\ rrice@chamberlain.edu (R. Rice),jhunter@chamberlain.edu (J. Hunter), jraithel@chamberlain.edu (A. Raithel), \\ rkirschner@chamberlain.edu (R. Kirschner)
}

\section{To cite this article:}

Robyn Rice, Joyce Hunter, Ann Raithel, Robin Kirschner. Innovative Art Therapy Activities Used by Undergraduate Student Nurses with Mental Health Patients. American Journal of Nursing Science. Vol. 7, No. 4, 2018, pp. 147-151. doi: 10.11648/j.ajns.20180704.16

Received: May 15, 2018; Accepted: June 7, 2018; Published: July 5, 2018

\begin{abstract}
The purpose of this paper is to describe specific art therapy activities that student nurses may use as intentional communication tools when interacting with mental health patients in the clinical setting. The suggested art therapy activities in this paper reflect a review of the evidence as well as over 30 years of nursing faculty field experience in the mental health clinical setting. Student nurses can use basic coloring or drawing activities to enhance communication with mental health patients. For purposes of this discussion, art therapy is defined as the usage of crayons, coloring, paper, and drawing.
\end{abstract}

Keywords: Art Therapy, Mental Health Nursing, Student Nurses, Therapeutic Communication

\section{Introduction}

Undergraduate nursing students are typically required to complete a clinical experience with acute care mental health patients, frequently in the hospital setting within a locked ward. Student nurses may initially feel uncomfortable within this clinical environment because they have not yet learned how to approach, interact nor communicate with hospitalized patients with varying mental health states and diagnosis [1]. Again, this is a new clinical experience for nursing students and very challenging because mental health patient behaviors can be very perplexing and hard to predict. Moreover, mental health patients may experience hallucinations, thought disturbances, thoughts of suicide, and/or overtly sexual or aggressive behavior that are initially challenging and sometimes scary for student nurses to work with as novice practicing clinicians. Yet, student nurses are required to conduct mental health assessments and to professionally interact with as well as to therapeutically communicate with this very vulnerable population.

Therapeutic communication is commonly viewed as face to face interaction(s) with patients with a goal to promote patient physical and mental well-being. It is a key component of most mental health nursing curriculums and viewed as quite useful in working with patients who are experiencing forms of anxiety, depression, thoughts of suicide, and/or perceptual disturbances. Therapeutic relationships are relationships where the patient believes that the nurse understands what is going on with him or her and supports the patient. Empathy and trust are additional key elements of the therapeutic relationship [1-3]. Therapeutic relationships in nursing are enabling relationships with a goal to promote patient positive coping skills, socialization and personal growth [4]. In hospitalized mental health patients therapeutic relationships may aid in mental and cognitive stabilization with a goal for community independence.

Rice et al. (2017) reported that art therapy such as basic coloring and drawing to be a useful tool for student nurses to use to enhance therapeutic communication with mental health patients. The evidence also suggest that art therapy may also facilitate a sense of professional growth in undergraduate nursing students by enhancing student confidence and skills in communicating with mental health patients [1]. Ensuring a strong educational foundation for students requires nursing faculty to ask themselves: What specific art therapy activities can student nurses use as intentional communication tools with mental health patients? How is this to be done? What guidelines or instruction should we provide our students? 


\section{Background: Acute Mental Health and Art Therapy}

Mental health patients may experience a variety of medical disorders including schizophrenia, depression, and bi-polar disorders that can affect their thinking, decision making and problem solving skills [5]. Such disorders can also affect the patient's attention span, reality orientation, and mood. Mental health patients may experience feelings of suicide or hopelessness and may feel disconnected from their environment [1]. Mental health patients may also experience feelings of anger or frustration at being placed in a locked ward. This is particularly true for those patients who have been admitted to the acute care psychiatric unit on an involuntary basis and who do not want to be there.

Art often symbolizes how people feel, and, serves as means to communicate feelings. This is very relevant to the needs of mental health patients as many in this group have verbal and perceptual difficulties. Art becomes a useful "tool" to provide a "voice" to the voiceless in creating connections with unspoken mental health patients' thoughts [5].

Art therapy has been shown to improve mood and selfesteem with mental health patients [3]. The evidence also suggests that art therapy may be a non-threatening way of expressing patients' feelings while building positive coping skills $[1,6]$. Art therapy promotes socialization and improvements in patient self-esteem [2]. Mental health patients can work in groups drawing pictures and sharing work. Art therapy also helps mental health patients to actually accomplish something giving way to feelings of creativity and empowerment [1,7]. Smolarski, Leone, and Robbins (2015) reported that using art therapy and drawing improved mental health patients' mood and positive emotional expressions. It may reduce levels of anxiety, depression, and a variety of somatic complaints as well as promote patient cognitive function [3]. It has been demonstrated to enhance mental health patient attention and focus span promoting positive emotional expressions of self $[5,8]$. Art therapy may also help children and adolescents manage anxiety and depression [9]. It also represents a unique way for children to communicate feelings off loss [10]. Art therapy thus offers a number of positive benefits to patients experiencing various forms of mental stress across the lifespan [7-9].

\section{The Nature of the Problem: A Lack of Student Nurse Experience}

Undergraduate student nurses may feel awkward and ill at ease when beginning their mental health clinical as related to the newness of their situation and fear of saying the wrong things to mental health patients. They may be concerned about making mental health patients angry or otherwise upset. This lack of experience to select effective or best communication strategies with mental health patients may make nursing students initially silent and ill at ease in the clinical setting. Yet, the clinical experience requires an assessment of suicidal thoughts and mood as part of the clinical experience. In addition, nursing students are expected to have a meaningful interpersonal interaction with their assigned patient. Such interactions include a basic mental status assessment, talking to the patient regarding what brought them to the hospital, identifying patient positive coping skills to promote community independence including a medication review and encouraging general patient socialization skills. The next section of this paper describes art therapy activities as intentional communication tools that nursing faculty might teach student nurses as a means to encourage students to professionally interact and communicate with mental health patients.

\section{Application: Undergraduate Student Nurses' Usage of Art Therapy Activities with Mental Health Patients}

Table 1. Innovative Art Therapy Activities with Mental Health Patients.

\begin{tabular}{|c|c|c|}
\hline Goals & ctivities & Therapeutic Process \\
\hline Improved Focus & Color or draw & $\begin{array}{l}\text { The student nurse and mental health patient color together; the patient is able to move from a state of } \\
\text { distraction/upset to an improved mental state of focus and calm }\end{array}$ \\
\hline $\begin{array}{l}\text { Improved } \\
\text { Communication Skills }\end{array}$ & Color or draw & $\begin{array}{l}\text { The student nurse and mental health patient just "be" with each other developing a therapeutic space in } \\
\text { which to talk and practice comfortable silence; the patient develops a sense of trust and shares feelings }\end{array}$ \\
\hline Improved Mood & $\begin{array}{l}\text { Color or draw } \\
\text { positive or happy } \\
\text { images }\end{array}$ & $\begin{array}{l}\text { The student nurse and mental health patient color or draw positive images together; the student nurse then } \\
\text { discusses the meaning and value of these images to the patient; the patient's mood is improved and anxiety } \\
\text { lessened }\end{array}$ \\
\hline
\end{tabular}

Student nurse and mental health patient art therapy interactions should primarily occur in an open areas in the locked unit such as the dining room or in a place where the nursing instructor or staff can observe everyone as related to milieu safety reasons. Crayons and paper are all that are needed for basic coloring or drawing and sharp objects should be avoided for safety reasons. Student nurses should recognize that drawing and coloring are powerful tools for communication "Table 1." Mental health patients should be assured that everyone can draw and color regardless of his or 
her abilities.

Student nurses can be instructed in the pre-conference setting the following activities as intentional communication tools by nursing faculty [1]:

Use coloring or drawing as a means for assessing mental health patient expression of feelings

---Ask patients to draw how they are feeling as a point for discussion; "what does this picture mean to you? How does it make you feel?"

Use coloring or drawing as a means for promoting mental health patient reflection

---Ask patients to draw something that had a positive impact on their lives as a point for discussion; "what is something good in this picture? What is its significance? How does it affect your life?"

Use coloring or drawing to identify positive mental health patient coping skills

---Ask patients to draw 5 positive coping skills as basis for discussion; "draw ways you can better deal with your sadness, stress or anger. How can you use these coping skills to help you? Describe some specific situations?"

Use coloring or drawing as a means for assessing mental health patient mood, anxiety levels and thoughts of suicide

---Assess what color of crayons the mental health patient is using; dark with negative images or bright and positive looking images; "rate your mood on a scale of 1-10 with 1 being a low mood and 10 being a high mood and anxiety on a scale of 1-10 with 1 being low feelings of being anxious and 10 feeling very anxious; do you have thoughts of harming yourself or others?"

Use coloring or drawing as a means for assessing mental health patient mindfulness, thought content, and reality orientation

----Ask the patient to draw the sunrise; "what does this picture of the sunrise mean to you?"

Use coloring or drawing to promote mental health patient socialization skills

----Implement coloring or drawing in mental health patient groups and encourage the sharing of pictures and group communication; "share your picture and tell us your story."

Use coloring or drawing as a tool to promote interpersonal rapport building with mental health patients:

----Implement coloring or drawing as a basis to initiate a conversation with the patient from simple to complex as the therapeutic relationships develops. Be comfortable with silence while coloring as this often represents an interaction of calm and trust; "tell me what has been going on with you since you last saw your doctor; since I last saw you?"

Use coloring or drawing as a tool to build mental health patient self-esteem and feelings of empowerment

---Implement coloring or drawing projects so that mental health patients may complete something; consider posting patient pictures on the walls in the unit dining room. Additionally, encourage mental health patients to take their pictures home and post them on their refrigerator to remind them that they can accomplish things. Praise their efforts; "good job with your drawing!"

\section{Discussion}

\section{Promotes the Student Nurse-Patient Therapeutic Relationship}

Art therapy activities such as basic coloring or drawing are important tools to encourage the development of the student nurse-patient therapeutic relationship. These activities offer a means for positive initial interpersonal interaction and seem to overcome some of the awkwardness that student nurses may feel in the acute care mental health clinical setting [1]. Such activities allow student nurses and mental health patients to focus on mutually identified clinical goals for the day building a sense a trust and empathy for each other as they interact.

Fosters Patient Reflection, Expressions of Feelings, and Positive Coping Skills for Community Independence

Art therapy activities allow mental health patients to draw out their feelings and express their selves in creative ways beyond words [11]. Such activities allow for pause and basic reflection enabling the patient to identify potential anger triggers as well as positive coping skills for recovery. Student nurses are certainly not therapists but they can assist mental health patients identify ways to handle conflict and despair in a healthy manner. Additionally, mental health patients report that just having someone like student nurses just "listen" to them express their feelings or tell their stories when doing something like drawing or coloring is helpful [1].

Establishes a Comfortable Silence

The authors of this paper have observed that student nurses and their patients at times just sit together in a somewhat "comfortable silence" just being present with each other while drawing or coloring. In fact, student nurses and mental health patients are often observed to be sitting very close to each other silently sharing crayons and paper. There seems to be a sense of closeness between the student nurse and mental health patient. They sit side by side and make direct eye contact. The acute care mental health milieu ---often an area of upset and patient tears becomes a place of quiet and calm. This silence is viewed as therapeutic and we turn to the literature and evidence to further understand manifestations of silence in communication.

The literature suggests that silence is an interval in the communication dialogue [11]. It also can manifest as patient withdrawal, distancing, and reflection [12]. However, some silences may in fact reflect patient engagement and interpersonal growth $[12,13]$. The evidence suggests that silence in art therapy does seem to promote a sense of patient connection with others and acceptance with graduations of evolving socialization [12]

In conclusion silence during art therapy activities appears to take on the form with student nurses and mental health patients just sitting and coloring or drawing together with no demands on each other as the therapeutic relationship deepens, builds and solidifies [1,14].

Encourages Student Nurse Proficiency in Assessing the Mental Health Patient and Performing the Mental Status Exam. 
Student nurses may feel initially awkward and uncomfortable asking if mental health patients are having thoughts of suicide as related to a lack of clinical experience in the mental health setting. Additionally, most student nurses are expected to complete a basic mental status assessment as part of their mental health clinical experience. This paper suggests that simple art therapy activities such as basic coloring or drawing make these assessments and patient interactions easier for student nurses as they allow a hands on and non-threatening approach with the patient [1]. Art therapy activities as intentional communication tools as described in this paper enable student nurses to assess and report mental health patient:

i. Mood

ii. Level of anxiety

iii. Thoughts to harm self or others (done each shift)

iv. Reality orientation

v. Basic thought content

vi. Basic positive coping skills

Promotes the Professional Growth and Development of the Student Nurse

Rice, Hunter, Spies, and Cooley (2017) reported that student nurses experienced a sense of professional growth when using art therapy such as basic coloring or drawing with mental health patients. Student nurses became less cautious and fearful of the clinical setting [1]. The clinical observations of the authors of this paper additionally confirm that student nurses' communication skills and clinical confidence tended to improve when using basic coloring or drawing when interacting with mental health patients. The clinical observations of the authors of this paper additionally confirm that art therapy activities used by student nurses such as basic coloring or drawing tend to reduce overall stress levels of student nurses and mental health patients; of note, the acute care mental health unit often becomes a calmer place once students appear on the unit and start saying hello to the patients.

Serves as a Basis for Human Creativity and Connection to Others

Last and probably most important to this discussion is that art therapy activities such as basic coloring or drawing provides a basis for human creativity. Creativity invokes human focus, reflection and self-expression; it also promotes a sense of socialization [2, 14]. These are key issues for mental health patients who often are in a state of despair and mental suffering with feelings of aloneness and disconnect.

In summary, it is important for nursing to recognize the importance of using art therapy activities such as basic coloring or drawing as a means to intentionally communicate with and support mental health patients. Usage of art therapy activities such as basic coloring or drawing provides hands on, cost effective clinical tools that supports communication between student nurses and mental health patients "Figure 1 ". This is particularly true at the beginning of the interaction when student nurses are trying to figure out what to say or just how to be with their patients.

\section{Future Directions}

This paper describes applications of art therapy activities as deliberate communication tools used by undergraduate nursing students. These art therapy activities were discussed in relation to the mental health setting but are applicable to many other areas of nursing. Art therapy activities as intentional communication tools may be useful in pediatric nursing clinicals as well as that of hospice where patients may find drawing or coloring an easier way for selfexpression. Art therapy activities can also be used in the classroom setting and in the simulation laboratory to encourage students to reflect on the true values of therapeutic communication. Art therapy activities can also be used in online education to engage students to interact globally across cultures.

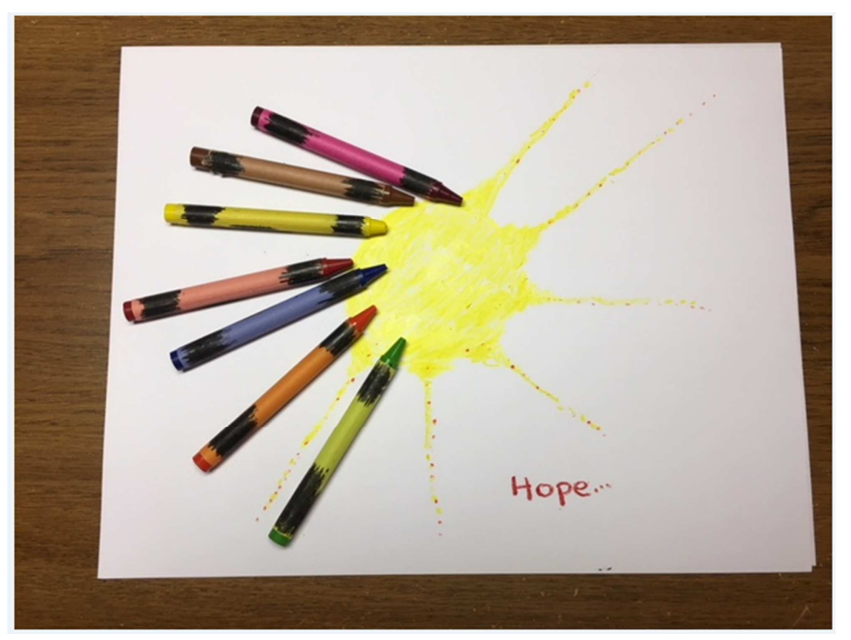

Figure 1. Crayons and Paper (Drawing Courtesy of Dr. Robyn Rice)

\section{Conclusion}

In conclusion, this paper has described student nurses' usage of art therapy activities such as basic coloring or drawing as intentional communication tools with mental health patients. An examination of the evidence as well as the authors' lengthy clinical field experiences in the acute care mental health setting provided the guidelines for this paper.

Student nurses can use art therapy activities as intentional communication tools to interact with mental health patients in a professional, creative, and non-threatening manner. Additionally, with these activities, mental health patients may "verbally open up" to their student nurse sharing thoughts, stories, and feelings as a path towards wellness. The authors believe that art therapy activities as intentional communication tools offer nurses ways of being with their patients beyond the technical; revealing many new realms of positive human interactions. Hence, the goal of using art therapy activities such as basic coloring or drawing as deliberate communication tools have applications in our nursing curriculum---- that we have yet to imagine. 


\section{References}

[1] Rice, R., Hunter, J., Spies, M., \& Cooley, T. (2017). Perceptions of nursing students regarding usage of art therapy in mental health. Journal of Nursing Education, 56 (10), 605610. doi: 10.3928/01484834-20170918-05.

[2] Potash, J. \& Rainbow, T. (2011). Drawing involves caring: Fostering relationship building through art therapy for social change. Journal of the American Art Therapy Association, 28 (2): 74-81.

[3] Maujean, A., Pepping, C., \& Kendall, E. (2014). A systematic review of randomized controlled studies of art therapy. Journal of the American Art Therapy Association, 31 (1): 3744.

[4] Berman, A., Snyder, S., \& Frandsen, G. (2016). Communicating. In A. Berman, S. Snyder, \& G. Frandsen(Eds.), Kozier an Erb's fundamentals of nursing: Concepts, process, \& practice $\left(10^{\text {th }}\right.$ ed., pp. 437-464). New York, Pearson

[5] Ali Hirani, A., Ghazal, L., Ali Kahalan, Z., Shafiq Dossa, K. (2016). Art therapy: an innovative approach in mental health settings. I-Manager's Journal on Nursing, 5(4): 40-44.

[6] Van Lith, T. (2015). Art therapy as a mental health recovery tool for change and coping. Journal of the American Art Therapy Association, 32 (1): 5-12.

[7] Smolarski, K., Leone, K., \& Robbins, S. (2015). Reducing negative mood through drawing: comparing venting, positive expression, and tracing. Journal of the American Art Therapy Association, 32 (4): 197-201.

[8] Tahmasebi, Z., Maghsoudi, J., \& Talakoub, S. (2017). The effect of painting on depression in children with cancer undergoing chemotherapy. Iranian Journal of Nursing \& Midwifery Research, 22 (2): 102-105.

[9] Hill, K., and Lineweaver, T. (2016). Improving the short-term affect of grieving children through art. Journal of the American Art Therapy Association. 33( 2) : 91-98.

[10] Makin, S. \& Gask, L. (2011). 'Getting back to normal': The added value of an art-based programme in promoting 'recover' for common but chronic mental health problems. Chronic Illness, 8 (1): 64-75. doi: $10.1177 / 1742395311422613$.

[11] Dafna, R., Hadass, K., \& Snir, S. (2016). Silence during art therapy: The art therapist's perspective. International Journal of Art Therapy. 21 (3): 8694.http://dx.doi.org/10.1080/17454832.2016.1219754

[12] Frankel, Z., et. al. (2006). Assessing silent processes in psychotherapy: an empirically derived categorization system and sampling strategy. Psychotherapy Research, 16 (5): 627638 .

[13] Savett, L. (2011). The sounds of silence: Exploring lessons about silence, listening, and presence. Creative Nursing, 17(4), 168-173. http://dx.doi.prg/10.1891/1078-4535.17.4.168

[14] Gillam, T. (2013). Creativity and mental health care. Mental Health Practice, 16 (9): 24-30. doi: 10.7748/mhp2013.06.16.9.24.e807. 